\title{
PENGARUH NEOSUFISME TERHADAP PERKEMBANGAN TASAWUF DAN TAREKAT BARU
}

\author{
Mahrus As'ad \\ STAIN Jurai Siwo Metro \\ Jl. Ki Hajar Dewantara 15A, Kota Metro, Lampung, 34111 \\ e-mail:mahrusasad@yahoo.co.id
}

\begin{abstract}
Abstrak: Tulisan ini mengkaji pengaruh neosufisme terhadap kontinuitas doktrin tasawuf dan tarekat-tarekat baru yang timbul sejak dua abad terakhir periode pertengahan Islam. Kemunculan neosufisme abad ke-14 M berpengaruh besar terhadap corak tasawuf dan tarekat baru abad-abad tersebut. Selain mendorong "purifikasi" doktrin agar tidak dimasuki unsur-unsur non Islam, neosufisme juga memberi arah baru agar tasawuf dan tarekat senantiasa berada dalam bimbingan syariat. Orientasi ini tidak saja memperlemah doktrin emanasi Tuhan atas makhlukNya berganti dengan doktrin transendensi, tetapi juga menjadikan tasawuf berada dalam kerangka ortodoks, tarekat juga demikian. Pengembalian ajaran ke sumber asli al-Qur'an dan Sunnah membuat tarekat-tarekat baru yang muncul bebas dari sifat yang tidak islami. Neosufisme berhasil mengubah orientasi tasawuf dan tarekat baru, yang lebih aktif-responsif terhadap urusan duniawi.
\end{abstract}

\begin{abstract}
The Influence of Neosufism towards the Development of Tasawuf and New Tarekat. This essay studies the influence of neosufism on the continuity of tasawuf doctrine and new tarekats emerged during the last two centuries of medieval Islamic period. The raise of the fourteeth century neosufism movement had greatly influenced the nature and the characteristics of the new tasawuf and tarekats of the succeeding era. In addition to giving impetus in 'purification' of the doctrines to avoid the tasawuf and tarekat from intrusion of un-Islamic elements, the neosufisme has provided with guidance so that they should be kept under the syariat control. This new tendency has forced the tasawuf and tarekats to weaken their support to the doctrin of immanation of God toward His creatures, and replaces it with the transcendent doctrine. The return to the original stipulations of the Qur'an and the Sunna liberated the tasawuf and tarekats from their un islamic characters. The Neosufism movement had succeeded in changing the orientation of the new tasawuf and tarekas to be more responsive to the worldly interest.
\end{abstract}

Kata Kunci: neosufisme, purifikasi, ortodoksi, aktivisme 


\section{Pendahuluan}

Sebagai bagian dari Islam, tasawuf dan tarekat banyak mendapatkan sorotan dari banyak pihak. Ajaran tasawuf dan amalan-amalan tarekat memang menimbulkan kontroversi dan perdebatan panjang. Ketika ajaran tasawuf dikuatkan kembali oleh al-Ghazâlî menjelang saat-saat keruntuhan Dinasti 'Abbasiyah, terjadi pertikaian sengit antara kaum sufi di satu pihak dengan kaum syari'at dan para teolog di pihak lain. Kedua kelompok terakhir ini dengan pendekatan legalistik formalistik menuduh tasawuf telah menyeleweng dari ketentuan-ketentuan syariat dan tauhid. Ajaran tasawuf seperti diperlihatkan oleh alHallâj, Abû Yazid al-Bistamî, Râbi'ah al-Adawîyah, hingga Ibn 'Arabî, memang cenderung menjadi gerakan esoteris yang menjurus kepada panteisme (paham keserbatuhanan) yang berarti musyrik (menyekutukan Tuhan), dan berbagai penyimpangan atas kaidah-kaidah moral dan sosial pada umumnya yang kemudian memeroleh pijakannya dalam kelembagaan tarekat. Ketika kebangunan kembali Islam diproklamirkan oleh kaum pembaru (modernis), tasawuf atau tarekat kembali dikambing-hitamkan sebagai penyebab kemunduran Islam. Mereka menyalahkan cara hidup sufi dan para pengikutnya yang berorientasi zuhd (sederhana) dan mengasingkan diri dari kehidupan ('uzlah), dengan jalan murâqabah (meditasi) yang hanya memikirkan rahasia-rahasia wujud Ilahi sebagai penyebab kemunduran umat Islam. Akibatnya, umat Islam kehilangan kepemimpinan dan semangat untuk mengatasi kemunduran guna mencapai kemajuan. Kehidupan tasawuf yang sangat menitik-beratkan pada pendekatan diri kepada Tuhan mengakibatkan kesenjangan pada kehidupan keduniaan. ${ }^{1}$

Namun, kemunculan neosufisme di abad ke-14 telah menimbulkan optimisme baru akan masa depan tasawuf dan tarekat dalam Islam guna menghadapi berbagai problem kehidupan kaum Muslim di masa modern yang semakin rasionalistik, materialistik dan konsumeristik. Dipelopori Ibn Taimîyyah (w. 728 H/1328 M) dan muridnya, Ibn Qayyîm (w. 751 H/1350 M), neosufisme atau tasawuf yang diperbarui telah membawa perubahan corak dan orientasi tasawuf yang penting. Dalam tarekat, perubahan paling menonjol terjadi tidak saja pada segi doktrin, tetapi juga pada segi orientasi dan bentuk organisasinya. Namun, tidak berarti tasawuf dan tarekat masa ini telah mengalami penggusuran total dari berbagai tradisi lamanya. Ada aspek yang masih dipertahankan, yaitu ajaran yang tidak bertentangan dengan syariat. Gejala kesinambungan doktrin, di samping perubahannya, juga terjadi pada tarekat yang muncul di masa-masa sesudahnya. Semua ini berakibat tidak saja pada perubahan citra tasawuf dan tarekat itu sendiri, tetapi juga warna Islam secara keseluruhan yang dipeluk kaum Muslim di kemudian hari. Seperti apa corak perkembangan masingmasing sangat ditentukan oleh lingkungan tempat keduanya tumbuh dan berkembang, serta menarik banyak pengikut. Menggunakan metode analitis-kritis, ${ }^{2}$ tulisan ini berusaha

${ }^{1}$ Azyumardi Azra, Esei-esai Intelektual Muslim dan Pendidikan Islam (Ciputat: Logos Wacana Ilmu, 1999) h. 98-99.

${ }^{2}$ Mengenai hakikat dan cara kerja metode ini, lihat Jujun S. Suriasumantri, "Penelitian Ilmiah, 
memahami dan menjelaskan pengaruh neosufisme terhadap kesinambungan dan perubahan doktrin tasawuf dan tarekat-tarekat baru yang timbul sejak Abad Pertengahan. Agar diperoleh gambaran yang jelas mengenai objek kajian, perlu terlebih dahulu dilakukan survei sosiohistoris untuk mengetahui latar belakang dan perkembangan doktrin kelembagaan tasawuf hingga melahirkan apa yang sering diistilahkan dengan neosufisme berikut ciri-cirinya yang membedakan dengan 'tasawuf lama'. Setelah itu, akan ditinjau secara singkat perkembangan kelembagaan tarekat sebelum dilanjutkan pembahasan mengenai reorientasi doktrin tasawuf dan munculnya tarekat baru.

\section{Perkembangan Doktrin dan Kelembagaan}

Secara historis, perkembangan tasawuf dalam Islam tidak dapat dipisahkan dengan gerakan zuhud (zuhd, ascetism) di kalangan kaum Muslim abad ke-1 H/7 M, ${ }^{3}$ yang merupakan gerakan protes dari sekelompok orang salih terhadap penguasa Umayah yang dianggap kurang religius dan bertentangan dengan kesalihan dan kesederhanaan hidup Nabi Muhammad SAW. dan empat khalifah sesudahnya. ${ }^{4}$ Sedih melihat kebatilan dan kezaliman dari kalangan atas, orang-orang salih yang bersikap serba agamis tersebut berusaha menarik diri dari masyarakat sambil melancarkan kritik. ${ }^{5}$ Gerakan mereka lebih diarahkan pada tindakantindakan moral dan cenderung menolak bentuk-bentuk kekerasan. Yang tergabung dalam kelompok ini adalah orang-orang salih yang mencurahkan hidup sepenuhnya untuk beribadat kepada Tuhan. Hasan al-Bashrî (w. 110 H.), seorang tokoh teolog besar dan terkenal salih, adalah wakil terkemuka dari kelompok ini. ${ }^{6}$

Selama abad ke-2 H/8 M, sebagai ekses dari menonjolnya pendekatan serba fikih dan kalam dalam kehidupan kaum Muslim, terutama di Basrah, muncullah kelompok anti ritualistik yang menekankan pada pentingnya aspek-aspek kesalihan yang lebih tinggi, yang pada gilirannya menyebabkan terjadinya pendalaman dalam aspek zuhud. Pada masa ini, zuhud bukan sekedar penarikan diri dari kehidupan masyarakat umum, tetapi bahkan lebih menjurus pada pengertian humilitas (kepapaan) yang tidak lagi hirau dengan masalah makanan dan pakaian. ${ }^{7}$ Konsep al-Qur'an tentang tawakkul yang semula berkonotasi etis, kini berkembang menjadi doktrin ekstrim tentang pengingkaran dunia, yang akhirnya

Kefilsafatan, dan Keagamaan: Mencari Paradigma Kebersamaan," dalam Mastuhu dan Deded Ridwan (ed.), Tradisi Baru Penelitian Agama Islam Tinjauan Antardisiplin Ilmu (Bandung: Nuansa, 1998) h. 41-60.

${ }^{3}$ Reynold A. Nicolson, "Sufism," dalam James Hastings, Encyclopaedia of Religion and Etics, Vol. XXII (Charles Scriber's, t.t.) h. 10; Abû al-Wafa' al-Ghânimî al-Taftazanî, Sufi dari Zaman ke Zaman, terj. Ahmad Rofi' 'Utsmani (Bandung: Pustaka, 1983) h. 54.

${ }^{4}$ Fazlur Rahman, Islam (Chicago: The University of Chicago Press, 1979) h. 129.

${ }^{5}$ A.J. Arberry, Sufism: An Account of the Mystics of Islam (London: Mandala Books, 1979) h. $32-33$.

${ }^{6}$ Nicholson, "Sufism," h. 10.

${ }^{7}$ Ibid. 
melahirkan konsep sentral sufi, yakni hubungan manusia dengan Tuhan. ${ }^{8}$ Karenanya, zuhud sejati, dengan tetap berteguh pada syariat, berarti pengekangan nafsu dengan tujuan cinta kepada Tuhan tanpa pamrih. Kefakiran, rendah hati, dan pasrah adalah ciri utama sufi-sufi abad ini. Mereka mencintai Tuhan, tetapi pada saat yang sama, lebih takut pada-Nya. Atas dasar itu, Nicholson menempatkan posisi tasawuf masa ini di antara zuhd dan ma'rifat, lebih tepatnya ridha. ${ }^{9}$ Doktrin tasawuf Ibrâhîm bin Adam (w. 160 H.) dan Râbi'ah al-Adawîyah (w. 185 H.) bisa dijadikan contoh.

Pada abad ke-3 H/9 M, tasawuf memasuki era baru. Selain pembentukan doktrin, terjadi peralihan konkrit dari paham zuhud ke konsep tasawuf dalam arti sesungguhnya. Para sufi yang sebelumnya disebut zahid memperkenalkan konsep-konsep baru yang baku, seperti ma'rifat, fana', hulûl, dan sebagainya, yang menjadikan tasawuf lebih sempurna, hingga kemudian melahirkan ilmu tasawuf. ${ }^{10}$ Dari segi doktrin, tasawuf abad ini dibedakan ke dalam dua aliran, yakni Khurasan dan Baghdad. Aliran Khurasan ditandai dengan penekanannya pada doktrin tawakkul (kepasrahan mutlak pada kehendak Tuhan), cenderung spekulatifpanteistik, mengabaikan ketentuan-ketentuan syariat, dan merusak tradisi ritual kaum Muslim yang sudah lazim. Tasawuf al-Bisthâmî (w. 201 H) dengan doktrin fana'nya serta

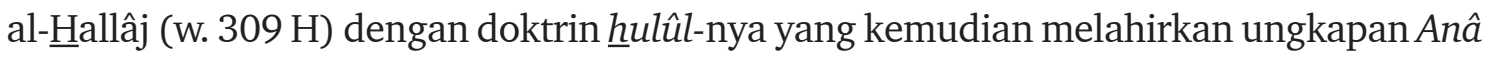
al- $\underline{H}$ aq dapat dijadikan contoh. ${ }^{11}$ Sedangkan, aliran Baghdad lebih menekankan kezuhudan dan kesalihan, cenderung menolak asketisme radikal, menjauhi doktrin fana', dan tetap berpegang teguh pada ketentuan-ketentuan syariat, di samping menghidupkan tradisi peribadatan kaum Muslim pada umumnya. Hârits al-Muhâsibî (w. 243 H) dan muridnya al-Junaid alBaghdadî (w. 298 H) merupakan eksponen utama aliran ini, yang berkat murid-muridnya kelak memunculkan tarekat dalam Islam. ${ }^{12}$

Selama abad ke-4 H/10 M, terjadi ketegangan antara kedua aliran tasawuf tersebut. Atas dukungan ulama ortodoks, aliran Baghdad berhasil memenangkan pengaruh, dan aliran Khurasan untuk sementara tenggelam. Munculnya sejumlah teoritisi handal, seperti al-Sarrâj (w. 377 H/987 M), penulis al-Luma', dan al-Kalâbâdzî (w. 390 H/995 M), penulis al-Ta'arruf, serta al-Qusyairî (w. 465/1073 M), penulis al-Risâlat, menjadikan aliran Baghdad berhasil merangkul golongan ortodoks, dan membawa tasawuf terintegrasi dengan syariat. Gerakan ini mencapai puncaknya pada gagasan dan tokoh al-Ghazâlî (w. 505 H/1111 M) yang berhasil membawa tasawuf ke posisi terhormat di kalangan Sunni. ${ }^{13}$ Gagasan al-Ghazâlî dengan

${ }^{8}$ Rahman, Islam, h. 130.

${ }^{9}$ Nicholson, "Sufism", h. 10.

${ }^{10} \mathrm{Al}$-Taftazani, Sufi, h. 17 dan 139.

${ }^{11}$ Ira M. Lapidus, History of Islamic Societies (Cambridge: Cambridge University Press, 1993) h. 112.

${ }^{12} \mathrm{Ibid}$.

${ }^{13}$ D.B. MacDonald, "Sufism," dalam E.J. Brill's First Encyclopedia of Islam, Vol. III (London: E.J.Brill, 1987), h. 149. 
tasawuf moderatnya, tidak saja telah merekonstruksi Islam ortodoks dengan menjadikan tasawuf sebagai bagian integralnya, tetapi juga berhasil membersihkan tasawuf dari unsurunsur yang tidak Islam. ${ }^{14}$

Namun, di sisi lain, keberhasilan metodologi tasawuf al-Ghazâlî pada saat bersamaan juga menjadi titik balik yang penting bagi berkembangnya doktrin tasawuf teosofi, seperti yang pernah muncul dalam aliran Khurasan. Yang sangat menonjol adalah berkembangnya ajaran Ibn 'Arabî dengan doktrin wahhdat al-wujûd (kesatuan wujud), yang akar-akarnya sebenarnya sudah ditancapkan oleh Dzû al-Nûn al-Mishrî (w. 860 M) dengan ajaran almárifat-nya. ${ }^{15}$ Menurut para pengikut doktrin ini, wujud itu satu; semua yang tampak banyak sesungguhnya satu kesatuan; dan semua yang tampak itu merupakan wujud luar Tuhan. ${ }^{16}$ Inilah doktrin sentral tasawuf dalam Islam, yang merupakan puncak dari teori tasawuf sufi-sufi abad ke-7 H/13 M dan sesudahnya. ${ }^{17}$ Tetapi, karena dianggap menyimpang dari ajaran Islam dan dituduh menjadi penyebab diabaikannya syariat, doktrin wahldat al-wujûd tidak pernah bebas dari kritik dan serangan dari golongan ortodoks.

\section{Kemunculan Neosufisme dan Pengaruhnya terhadap Doktrin Tasawuf}

Sebagai reaksi atas meluasnya penyebaran pengaruh doktrin wah̆dat al-wujûd, muncul di kalangan ulama ortodoks gerakan pembaruan tasawuf yang kemudian menghasilkan apa yang sering disebut dengan istilah neosufisme atau tasawuf baru. Dipelopori Ibn Taimîyyah (w.728 H/1328 M) dan muridnya Ibn Qayyim (w.751 H/1350 M), neosufisme dimaksudkan sebagai tasawuf yang diperbarui (reformed sufism), dengan mana sebagian besar sifat ekstatikmetafisis dan kandungan mystiko-filosofis yang sebelumnya dominan dalam tasawuf lama, kini digantikan kandungan yang tidak lain daripada postulat-postulat agama (Islam) ortodoks.

Neosufisme menekankan dan memperbarui faktor moral asli dan kontrol diri puritanis dalam sufisme dengan mengorbankan bentuk-bentuk ekstravaganza sufisme populer yang tidak ortodoks. Dengan membangun tasawuf berpangkal pada dan senantiasa di bawah al-Qur'an dan hadis, neosufisme berusaha mengalihkan pusat perhatiannya kepada rekonstruksi sosio-moral masyarakat Muslim tanpa harus meninggalkan keaktifan dalam kehidupan nyata. ${ }^{18}$ Singkatnya, neosufisme menekankan perlunya pelibatan diri individu dalam masyarakat secaralebih kuat daripada tasawuflama, yang lebih menekankan kepentingan hidup perseorangan. ${ }^{19}$

${ }^{14}$ Rahman, Islam, h. 140.

${ }^{15}$ S.A.Q. Husaini, The Pantheistic Monism of Ibn Arabi (Lahore: S.H. Muhammad Ashraf, 1970) h. 21.

${ }^{16}$ Nicholson, "Sufism," h. 15.

${ }^{17}$ Cyril Glasse, The Consise Encyclopedia of Islam (London: Stancey International, 1989), h. 414.

${ }^{18}$ Rahman, Islam, h. 193.

${ }^{19}$ Ibid, h. 194. 
Ciri utamanya adalah tekanannya pada motif moral dan penerapan metode $d z i k r$ dan murâqabat (konsentrasi kerohanian) guna mendekati Tuhan, tetapi dengan sasaran dan kandungan isi yang disejajarkan dengan doktrin salafi (ortodoks), bertujuan untuk meneguhkan keimanan kepada akidah yang benar serta kemurnian moral jiwa. ${ }^{20}$

Para pengikut tarekat baru ini cenderung menghidupkan kembali aktifisme salafi dan menanamkan sikap positif kepada dunia, dan sampai batas tertentu, menerima klaim kebenaran kasyf (pengalaman penyingkapan kebenaran Ilahi) kaum Sufi atau ilham intuitif, tetapi pada saat yang sama menolak klaim mereka yang seolah-olah tidak dapat salah (ma'shûm), dengan menekankan bahwa kehandalan kasyfadalah sebanding dengan keberhasilan moral kalbu, yang sesungguhnya mempunyai tingkat-tingkat yang tidak terhingga. Seperti diakui sendiri oleh Ibn Taimîyah dan Ibn Qayyim mengenai pengalaman kasyf mereka, yang hanya saja kejadiannya dibawa kepada tingkat proses intelektual yang sehat. Bahkan, Ibn Taimîyah dan para pengikutnya dikabarkan juga menggunakan seluruh terminologi kesufian, termasuk istilah sâlik (penempuh jalan kerohanian), dan mencoba memasukkan ke dalamnya makna moral yang puritan dan etos salafi. ${ }^{21}$

Mendapat pengakuan dan dukungan dari ulama ortodoks, neosufisme segera menjadi gerakan tasawuf baru dan berhasil menarik banyak simpati dari kalangan ulama sendiri, yang memang berkepentingan membersihkan tasawuf (lama) dari berbagai penyimpangan dan tambahan unsur luar (Islam). Pada akhir Abad Pertengahan, tasawuf dengan pendekatan barunya yang berusaha mengawinkan tasawuf kontemplatif-purifikatif dengan syariat dan teologi, sudah diterima sepenuhnya ke dalam pelukan ortodoksi (Sunni). Menariknya, gerakan reorientasi dan purifikasi doktrin tasawuf agar senantiasa sejalan dengan doktrin tasawuf baru (neosufisme) justru datang lebih awal dari kalangan internal tasawuf sendiri. Seorang tokoh sufi terkenal Ala al-Daulah al-Samnanî (w. 736 H/1336 M) mengkritik bahwa doktrin wahdat al-wujûd sebagai mencapuradukkan Tuhan dengan alam dan menyamakan yang Ilahiah dengan yang manusiawi.

Gerakan tersebut mendapatkan dukungan kuat dalam ajaran Ahmad al-Sirhindî (w. 1034 H/1625 M), seorang ulama sufi terkemuka dari tarekat Naqsyabandiyah India. Menurut Anshari, sebenarnya al-Sirhindî sependapat dengan Ibn 'Arabî bahwa alam ini satu dengan Tuhan dan merupakan penampakannya, tetapi berbeda dengan Ibn 'Arabî, bahwa alam adalah determinasi dari ketiadaan dengan pantulan wujud Tuhan, yang sebenarnya lain dari dan berbeda dengan wujud Tuhan. Pada hakikatnya, alam ini tiada dan bersifat ilusif belaka, dan hanyalah pantulan dari wujud Tuhan. Karena pantulan lain dari wujud Tuhan, hakikat dan keberadaan alam ini juga lain dari Tuhan. Menurut Ibn 'Arabî, alam ini secara substansi satu dengan Tuhan, keberadaannya adalah keberadaan Tuhan; ia adalah Tuhan dalam bentuk manifestasi keterbatasannya. Jika diadakan perbandingan, teosofi

\footnotetext{
${ }^{20} \mathrm{Ibid}$.

${ }^{21}$ Ibid., h. 195.
} 
Ibn 'Arabî bersifat monisme kosmik dan dapat digolongkan sebagai panteisme; sedangkan, teosofi al-Sirhindî, monisme akosmik yang menarik garis paham transendensi mutlak. ${ }^{22}$

Hanya saja, gagasan al-Sirhindî tidak dielaborasi secara lengkap dan menyeluruh. Namun, kritiknya terhadap doktrin wah̆dat al-wujûd benar-benar menggoncangkan dunia tasawuf. Gerakannya berpengaruh sangat luas, terutama di anak benua India, dan sukses dalam meniadakan kecenderungan-kecenderungan antinomi di kalangan tasawuf. Menurut Fazlur Rahman, keberhasilan al-Sirhindî memperbarui tasawuf melalui tasawuf yang sesuai dengan syariat dapat disejajarkan dengan prestasi Ibn Taimîyah. ${ }^{23} \mathrm{Hal}$ ini dapat diketahui dari munculnya beberapa tokoh sufi, yang sejalan dengannya, yang sementara tetap setia dengan konsep Ibn Aarabî, pada saat yang sama, memasukkan paham transendensi ke dalam sistem ajaran Ibn 'Arabî tersebut. Pembaru dan tokoh sufi terkemuka dari India Syâh Walî Allâh (w. 1176 H/1762 M) dan anaknya Syâh 'Abd al-'Azîz dapat dijadikan contoh dalam hal ini. ${ }^{24}$

Melalui proses agak panjang, gerakan neosufisme berhasil memberikan arah baru dan sekaligus "menjinakkan" doktrin tradisional tasawuf, meskipun tidak secara total. Jangkauan pengaruhnya meluas hampir ke seluruh kawasan dunia Islam, termasuk kawasan Melayu Indonesia. Tasawuf al-Rânîrî (w. 1666 M), dan al-Makâsarî (w. 1699 M), ${ }^{25}$ serta gagasan "tasawuf modern" Buya Hamka yang sangat terkenal, dapat dilacak akarnya dari doktrin neosufisme. ${ }^{26}$ Dengan tetap menjaga kesinambungan (continuity) doktrin tradisionalnya, neosufisme membawa perubahan (change) doktrinal sangat mendasar dalam rangka menjauhkan tasawuf dari paham yang menjurus kepada kesesatan. Kekuatan pendekatan ini, selain memungkinkan tasawuf tetap dapat mempertahankan doktrin wahdat al-wujûd-nya Ibn "Arabî, lewat interpretasi tentunya, secara sadar dan "cerdik" dapat mendamaikan doktrin tersebut dengan ajaran-ajaran ulama syariah. Dengan demikian, dapat dibedakan dengan jelas antara tasawuf orthodox dan tasawuf unorthodox yang harus dijauhkan.

Yang lebih penting lagi dari kecenderungan baru ini sebenarnya adalah perubahan aspek doktrinal yang dibawa neosufisme, yang mendorong doktrin ajaran tasawuf yang berkembang di masa-masa kemudian senantiasa berada dalam pengawasan syariat, dan syariat untuk selanjutnya tetap menjadi bagian tidak terpisahkan dari doktrin tasawuf. Perkembangan selanjutnya, sejak masuknya syariat ke dalam doktrin tasawuf dengan sendirinya semakin memperkokoh posisi Islam ortodoks, yang pada gilirannya turut memudahkan

\footnotetext{
${ }^{22}$ Abdul Haq Ansari, "Syah Wali Allah Attempts to Revise Wahdat al-Wujud," dalam Arabica (Leiden: E.J. Brill, 1988), h.197-213.

${ }^{23}$ Fazlur Rahman, "Islam: Challenges and Opportunities," dalam Alford T. Welch dan Pierre Cachia (ed.), Islam: Past Influence and Present Challenge (London: Edinburgh University Press, 1979).

${ }^{24}$ Rahman, Islam, h. 202.

${ }^{25}$ Azyumardi Azra, Jaringan Ulama Timur Tengah dan Kepulauan Nusantara Abad XVII dan XVIII (Bandung: Mizan, 1994).

${ }^{26}$ Nurcholish Madjid, Islam Agama Peradaban Membangun Makna dan Relevansi Doktrin Islam dalam Sejarah (Jakarta: Paramadina, 2000) h. 78.
} 
terjadinya rekonstruksi dan reformasi praktek tasawuf populer atau yang sering disebut dengan tarekat yang saat itu telah mengalami degradasi pamor, karena terkontaminasi dengan berbagai kepercayaan dan amalan-amalan dari luar Islam. Sejauh mana neosufisme selanjutnya mampu mempengaruhi terjadinya perubahan doktrin dan orientasi tarekat atau sehingga mengantarkannya kembali kepada pangkuan ortodoksi Islam, elaborasi berikut ini diharapkan dapat memberikan penjelasan.

\section{Terbentuknya Kelembagaan Tarekat}

Istilah tarekat (Arab: tharîqat), secara harfiah berarti "jalan" (sabîl), ${ }^{27}$ yang dalam literatur sufi memiliki dua pengertian, individu dan kolektif, yang hanya dapat dijelaskan melalui proses kesejarahannya. Tarekat dalam pengertian pertama adalah suatu metode kerohanian untuk memberikan bimbingan spiritual kepada seseorang sâlik dalam mengarahkan kehidupannya menuju kedekatan diri dengan Tuhan. ${ }^{28}$ Tarekat dalam pengertian ini merupakan jalan yang harus ditempuh atau diikuti seorang, lewat mana sejumlah maqâmât dan aḩwâl harus dilampaui untuk sampai kepada tujuan akhir, yaitu ma rifat dengan Tuhan. ${ }^{29}$ Inilah fase kala mana istilah tarekat menunjukkan arti aslinya, sebagai sebuah metode atau jalan spiritual yang harus ditempuh seseorang sâlik untuk sampai kepada yang Maha Benar (Tuhan). Singkatnya, tarekat dalam pengertian ini berkonotasi individual di mana kehidupan sufistik menjadi ciri utamanya.

Bergesernya sifat individual ke sifat kolektif dalam bentuk persaudaraan sufi terjadi selama abad ke-3 H. dan ke-4H. atau abad ke-9 M. dan abad ke-10 M. menyusul terselenggaranya halaqah-halaqah kecil antara seorang guru sufi dengan sejumlah pengikutnya dalam sebuah organisasi yang tidak tetap dan masih longgar, berkembang menggunakan pusat-pusat pertemuan sufi, seperti zâwiyah, ribâth, khânqâh, atau tekke, yang sekaligus berfungsi sebagai tempat pendidikan sufi dilaksanakan. ${ }^{30}$ Dengan makin bertambahnya aktifitas dan jumlah pusat-pusat pertemuan sufi dari waktu ke waktu, teori-teori, konsep-konsep, dan amalanamalan mistis diperkenalkan, begitu juga tata tertib untuk mengatur kehidupan bersama. Pada pertengahan kedua abad ke- 6 H/12 M ketika semuanya telah mencapai kemapanan, tarekat kemudian menjelma ke dalam pengertian kedua, yaitu sebagai persaudaraan sufi atau ordo (sufi brotherhood). ${ }^{31}$ Dalam pengertian kedua, tarekat berarti komunitas di mana sejumlah sufi bergabung dengan seorang guru (syaikh) dan tunduk di bawah aturan-aturan tertentu, secara kolektif di pusat-pusat pertemuan sufi maupun pertemuan-pertemuan

${ }^{27}$ Abu Louis Ma'luf, Al-Munjid fí al-Lughah wa al-A lâm (Beirut: Dâr al-Masyriq, 1986) h. 465.

${ }^{28}$ Louis Massignon, "Tarika," dalam E.J. Brill's First Encyclopaedia of Islam (Leiden: E.J. Brill, 1987) h. 467.

${ }^{29}$ A.H. Johns, "Tariqah," dalam Mircea Eliade (ed.), The Encyclopaedia of Religion (New York: Macmillan Publishing Company, 1987), h. 342.

${ }^{30}$ Phillip K. Hitti, History of the Arabs (London: Macmillan, 1973) h. 439.

${ }^{31}$ Johns, "Tariqah," h. 344. 
rohani lainnya secara periodik. ${ }^{32}$ Secara garis besar, keanggotaan tarekat dalam arti kedua ini dapat dibedakan menjadi dua jenis: selain (calon) anggota perkumpulan yang sesungguhnya, terdapat juga-biasanya-beberapa asosiasi atau warga masyarakat umum yang datang kapan saja untuk mendapatkan wejangan dari sang guru sufi, di sela-sela menjalani aktifitas kesibukan hidup sehari-hari. Tarekat-tarekat periode inilah yang kemudian menjelma menjadi tarekat-tarekat besar sekarang ini yang banyak sekali jumlahnya, dengan sebutan bermacammacam sesuai nama sang pendiri.

Tarekat paling tua muncul di Irak, tepatnya di Baghdad, bernama tarekat Qâdirîyah, mungkin paling banyak pengikutnya, pendirinya adalah 'Abd al-Qâdir al-Jîlânî (w. 525 H/1131 M), Suhrawardîyah yang pendirinya adalah 'Abd Qâhar Abû Najib al-Suhrawardî (w. 578 H/1182 M), dan Rifâ̂îyah di Bashrah, pendirinya Ahmad Rifầî (w. 578 H/1162 M). Di Turki, berdiri tarekat Yasawîyah dan Maulawîyah, pendirinya masing-masing Aḥmad Yasafí (w. 562 H/1166 M) dan Jalâl al-Dîn Rûmî (w. 672 H/1273 M). Di Afrika Utara, tarekat Syâdzilîyah, pendirinya Abû al-Hasan al-Syâdzilî (w. 656H/1258 M); di Mesir tarekat Ahmadîyah (Badawîyah), pendirinya Ahmad al-Badawî (w. 675 H/1275 M); di Persia tarekat Kubrawîyah dan Khalwatîyah, pendirinya masing-masing Najm al-Dîn Kubra (w. 618 H/1221 M) dan 'Umar al-Khalwatî (w. 1397 M). Di Asia Tengah, tarekat Naqsyabandiyah, pendirinya Bahâ' al-Dîn Naqsyabandî (w. 791 H/1389 M); dan di India tarekat Chisytîyah pendirinya Mu'în al-Dîn Chisytî (w. 633 H/1236 M). Di luar mereka, banyak tarekat lain, induk maupun cabang, muncul di dunia Islam dari berbagai generasi hingga abad ke-9 H/16 M. Jumlah mereka secara keseluruhan, dalam penghitungan al-Attas, mencapai 177 ordo. ${ }^{33}$ Meski demikian, secara doktrinal-objektif, pada dasarnya tidak terdapat perbedaan mendasar antara satu tarekat dengan yang lain, kecuali aspek ritualnya, seperti dalam metode dan bacaan $d z i k r$ dan amalan peribadatannya. Tarekat Rifâîyah, misalnya, lebih menyukai dzikr keras, sedangkan Naqsyabandîyah, $d z i k r$ yang sedang-sedang saja. Dalam segi tujuan, tarekat-tarekat yang jumlahnya banyak dan bermacam-macam itu pada dasarnya sama untuk meningkatkan kualitas moral-spiritual sesuai dengan ajaran agama (Islam). ${ }^{34}$

Sejak masa pembentukan, pergerakan dan penyebaran tarekat lincah sekali dan bisa memasuki hampir semua lini kehidupan kaum Muslim. Di kalangan penguasa para sufi biasa mendapat perlindungan dan perlakukan khusus, dan bahkan bisa memasuki jaringanjaringan khusus. Dengan ulama ortodoks, mereka bisa bekerja sama sehingga memudahkan syariat terintegrasi dengannya. Di kawasan perbatasan Afrika Utara, Asia Tengah, dan India tarekat bisa bergabung dengan para pejuang Islam, sehingga dapat berperan penting dalam proses islamisasi. ${ }^{35}$ Di masyarakat bawah pengaruhnya lebih hebat lagi. Di sini, pelayanan

${ }^{32}$ J.S. Trimingham, The Sufi Orders in Islam (Oxford University Press, 1979).

${ }^{33}$ Syed Muhammad Naquib al-Attas, Some Aspects of Sufism as Understood and Practiced Among the Malays (Singapore: Malayan Sociological Research Institute Ltd., 1983) h. 31.

${ }^{34}$ Arbery, Sufism, h. 89.

${ }^{35}$ Lapidus, History, h. 171. 
guru-guru sufi tidak hanya berbentuk pemberian bimbingan spiritual, tetapi mencakup juga perlindungan dan pelayanan sosial bersifat konkrit bagi siapa saja yang memerlukan, termasuk pembebasan mereka yang sedang ditahan para penguasa. Tempat tinggal mereka, zâwiyah, selain terbuka untuk umum, biasa digunakan para musafir dan pedagang sebagai tempat menginap, si miskin memeroleh bantuan, dan orang-orang sakit mendapatkan perawatan. ${ }^{36}$

Secara geografis, penyebaran tarekat tidak mengenal batasan wilayah. Ada yang penyebarannya hanya di seputar tempat mula pertama mereka didirikan, ada yang bersifat regional. Namun tidak sedikit dari mereka menyebar hingga menembus batas-batas wilayah Islam lainnya. Tarekat Qâdirîyah bermula di Baghdad, tetapi kemudian menyebar sangat menyolok di Yaman, Mesir, Sudan, Maghrib, Afrika Barat, India, dan Asia Tenggara. Tarekat Naqsyabandiyah, walaupun berdiri di Bukhara, memainkan peranan penting di India, dengan cabang-cabangnya di Cina, Asia Tengah, Timur Tengah dan Indonesia. ${ }^{37}$ Menurut Johns, ada beberapa faktor yang memudahkan penyebaran tarekat. Selain daya tarik esoterikbatiniahnya, pengakuan dan penerimaan tasawuf oleh ulama ortodoks, munculnya kekacauan dan ketidakpastian hidup menyusul tumbangnya kekhilafah 'Abbasyiah di Baghdad di tangan tentara Mongol, dan jatuhnya kaum Muslim ke tangan penguasa non-Islam di kemudian hari, menjadi pendorong yang kuat bagi kaum Muslim untuk memasuki tarekat. ${ }^{38}$ Dalam situasi ketidakberdayaan menyeluruh, tarekat yang secara rohani menawarkan keakraban sosial tanpa pilih kasih, sangat mudah menjadikan dirinya alternatif bagi afiliasi sosial secara menyeluruh. Terlebih lagi sejak mendapat restu dari ulama ortodoks, tarekat bisa menjadi semacam "rumah besar" yang hangat, yang bisa memberi tempat perlindungan jasmaniruhani kepada siapa saja yang memasukinya. ${ }^{39}$

Memainkan peran beragam, tarekat pada masa jayanya hampir tidak dapat dipisahkan dari Islam, termasuk islamisasi dan penguatannya di berbagai wilayah baru. Ketangguhan dai-dainya dalam memasuki berbagai wilayah baru hingga ke pedalaman-pedalaman, tidak disangsikan lagi, mempunyai kontribusi penting bagi penyebar-luasan Islam, yang dampaknya masih bisa dirasakan hingga sekarang. Jika saja tidak berkembang tarekat dalam Islam, sulit dibayangkan agama ini mampu menyebar dan dikenal secara luas ke berbagai wilayah yang sering disebut periferal (pinggiran) seperti Afrika Barat ${ }^{40}$ dan Indonesia. ${ }^{41}$ Begitu sentralnya peran tarekat dalam sejarah Islam Abad Pertengahan menjadikannya hampir identik dengan Islam. Artinya, menjadi anggota tarekat sama dengan menjadi Muslim, demikian pula sebaliknya.

Namun, sejak naiknya Dinasti 'Utsmani (abad ke-8 H/15 M), khususnya pada dua abad

\footnotetext{
${ }^{36}$ Johns, "Tariqah," h. 344.

${ }^{37}$ Ibid., h. 347-348.

${ }^{38}$ Ibid., h. 344.

${ }^{39}$ Ibid.

${ }^{40}$ Bassam Tibi, Krisis Peradaban Islam Modern: Sebuah Kultur Praindustri dalam Era Ilmu Pengetahuan dan Teknologi, terj. Yudian W. Asmin et al. (Yogyakarta: Tiara Wacana, 1994), h. 86-91.

${ }^{41}$ Martin van Bruinessen, Tarekat Naqsyabandiyah di Indonesia (Bandung: Mizan, 1998).
} 
terakhir, pamor tarekat terus mengalami degradasi, dan secara perlahan tetapi pasti berubah menjadi gerakan sufisme popular, dengan membentuk cabang-cabang ke dalam berbagai macam aliran. Dalam keadaan seperti ini, tidak tertutup kemungkinan terjadinya kompromi antara yang ideal dan yang praktis dari tarekat-tarekat dengan kepercayaan umum-lokal. Kecenderungan massa Muslim seperti ini pada gilirannya mendorong terbaginya Islam ke dalam berbagai varian keagamaan, yang bertentangan dengan semangat universalisme yang diperjuangkan ulama ortodoks. Hingga abad ke-12, universalisme Islam tersebut relatif terjaga ketika semuanya masih berada di bawah dominasi ulama ortodoks. Tetapi, pada abad-abad sesudahnya, ketika gelombang islamisasi lewat tarekat dan tasawuf terus mengalami peningkatan secara massif, pada saat bersamaan, Islam "yang sebenarnya" semakin tenggelam, atau setidaknya mengalami tekanan. Masuknya elemen-elemen pra atau non Islam ke dalam tarekat-tarekat di Mesir, Asia Tengah, Eropa Timur dan Indonesia, dapat dijadikan contoh. ${ }^{42}$

Menurut Trimingham, ada dua faktor yang menyebabkan mundurnya pamor tarekat. ${ }^{43}$ Pertama, faktor internal akibat ketidakmampuan kalangan guru sufi menghasilkan karyakarya kreatif, di luar komentar-komentar (syarh ) atau ikhtisar atas karya tokoh-tokoh sufi sebelumnya. Kedua, faktor eksternal akibat kecenderungan formalisme di kalangan pengikut tarekat atau tasawuf hingga menjauhkan keduanya dari substansi ajaran sebenarnya. Sebagai gantinya, tarekat atau tasawuf lebih banyak menyibukkan diri dalam perbincangan tidak penting, seperti tentang biografi para wali dan kedudukan khusus atau kekeramatan mereka yang pada gilirannya menjurus ke arah kultus. Semua ini menggiring para pengikut tarekat atau tasawuf ke arah pandangan dan kebiasaan hidup yang sekarang sering diistilahkan dengan khurâfât, tahayul dan bid'ah, yang sebenarnya tidak dikehendaki oleh guru-guru guru sufi pendiri tarekat serta ajaran Islam sendiri. Kata Lapidus, kecenderungan kultus wali sufi dalam kehidupan tarekat dan tasawuf terkait dengan teori wilâyât-nya al-Hâkim al-Tirmidzî (w. 898 H), yang menyatakan bahwa seorang sufi adalah wali, yang lewat pencapaian spiritualnya mampu menegakkan tatanan hidup di bumi, dan karena kekeramatan yang diberikan Tuhan kepadanya dapat menjadi perantara bagi orang-orang awam dalam berhubungan dengan Tuhan. ${ }^{44}$

Dalam kondisi massa Muslim semakin mengalami kemerosotan segi kepercayaan dan amaliah dalam hidup ketarekatan sehari-hari, mudah dimengerti mengapa selalu muncul gerakan-gerakan dari dalam tarekat sendiri, yang berusaha memurnikan kembali ajaranajarannya dari berbagai penyimpangan yang dibawanya. Pembaruan yang dibawanya, selain mengakibatkan perubahan dalam segi doktrin dan amalan-amalan tarekat-tarekat lama yang sudah besar dan mapan, sekaligus juga mendorong munculnya beberapa tarekat baru yang orientasinya lebih segar dalam menjaga kemurnian ajaran dari masuknya unsurunsur luar.

\footnotetext{
${ }^{42}$ Rahman, Islam, h. 154-155.

${ }^{43}$ Trimingham, The Sufi Orders, h. 103.

${ }^{44}$ Lapidus, History, h. 115.
} 


\section{Reorientasi Doktrin Tasawuf dan Munculnya Tarekat Baru}

Doktrin ajaran neosufisme, yang di kemudian hari mengejawantah dalam kehidupan pribadi-pribadi ulama-sufi serta para pendukungnya, dengan tegas menunjukkan bahwa dalam tasawuf sama sekali tidak ada lagi tempat bagi sikap pasif dan penarikan diri ('uzlah) dari masalah-masalah praktis duniawi. Dengan tetap memegangi al-Qur'an dan hadis, neosufisme membedakan dirinya dengan paradigma tasawuf awal yang sering menjerumuskan orang ke dalam pasivitas, justru sangat menekankan aktivisme. Melalui tokoh-tokohnya, neosufisme menghimbau kaum Muslim sedemikian rupa agar aktif memenuhi kewajiban duniawi, yang seakan-akan menjadi maqâm tersendiri yang harus dilalui dalam rangka mencapai kemajuan dalam perjalanan mistis. Menurut mereka, sufi yang sebenarnya bukanlah sufi yang mengalienasikan diri dari masyarakat, melainkan sufi yang menyeru kepada kebaikan dan mencegah kemungkaran, membantu dan membebaskan mereka yang tertindas, orang-orang sakit dan miskin; yang dapat melakukan ta'âwun (tolong-menolong) dengan Muslim lain untuk kemajuan masyarakat. ${ }^{45}$ Dalam kasus ulama sufi Melayu abad ke-17, sifat aktifisme mereka jelas sekali kelihatan, yang ekspresinya tidak begitu jauh dengan yang diperlihatkan tokoh-tokoh tarekat pembaru. ${ }^{46}$

Seperti sudah disinggung di atas, di tengah merosotnya pamor tarekat secara umum, usaha pemurnian dan pembaruan di kalangan mereka juga tidak bisa dihindari. Lebih-lebih setelah terjadinya rekonsiliasi antara kalangan tasawuf dengan ulama ortodoks, yang berakibat semakin mendekatnya tasawufke dalam pangkuan syariat. Di kalangan Naqsyabandiyah India, misalnya, muncul gerakan al-Mujaddîdiyah di bawah ajaran Ahmad al-Sirhindî, yang menolak ajaran wahdat al-wujûd-nya Ibn Arabî, dan hendak mengembalikan tarekat ke pangkuan syariat, yang pengaruhnya bahkan sudah merembes hingga ke luar India dan mendominasi Hijaz di abad ke-18. Gerakan ini semakin penting pada abad ke-19 dengan tampilnya Maulana Khalîd, yang darinya kemudian muncul terekat Naqsyabandiyah-Khalîdîyah, untuk mendukung supremasi syariat dan aktivisme dalam kehidupan kaum Muslim. Pada akhir abad ke-18 gerakan pembaruan tarekat, dengan maksud yang sama, juga muncul di Indonesia (Minangkabau) di kalangan tarekat Syaththârîyah, yang sangat merosot coraknya, karena percampurannya dengan kepercayaan-kepercayaan lokal, yang terus berlanjut hingga munculnya tarekat baru Qâdirîyah-Naqsyabandiyah, dipelopori ulama

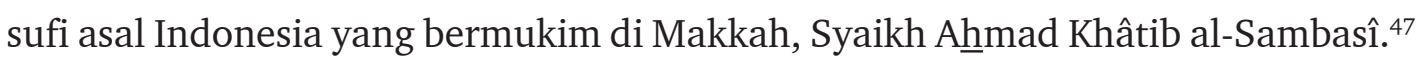

Namun, gerakan pembaruan tarekat ini baru mendapatkan momentumnya yang luar biasa dengan munculnya beberapa tarekat baru, seperti Tijânîyah, Idrîsîyah dan Sanûsîyah di kawasan-kawasan tertentu dunia Islam, terutama Afrika, di abad ke-18 dan awal abad

${ }^{45}$ Azra, Konteks Berteologi h.130.

${ }^{46}$ GWJ Drewes, "Futher Data Concerning "Abd al-Shamad al-Palembani," dalam BKI, 132 (1976) h. 269.

${ }^{47}$ Azra, Jaringan Ulama, h. 290-291. 
ke-19. Jika neosufisme mendukung aktifisme hidup duniawi, tanpa mengorbankan pemenuhan disiplin spiritualnya, ciri yang sama juga menandai tarekat-tarekat baru tersebut. Mereka menyerukan persatuan Islam, kembali kepada ajaran dasar al-Qur'an dan Sunnah, dan trandensi Tuhan atas ciptaan-Nya, serta pengamalan $d z i k r$ untuk tujuan-tujuan sederhana berdasarkan ajaran salafi. Mereka sangat mencela amalan-amalan tarekat klasik, seperti pencarian ektase, penghormatan kepada wali, masuknya praktek-praktek pra-Islam ke dalam ibadah dan menganjurkan penerapan syariat secara etat dalam tasawuf. ${ }^{48}$ Tujuan bertarekatnya pada dasarnya tidak berbeda dengan tarekat-tarekat lain sebelumnya, yaitu demi sempurnanya jiwa manusia, tetapi metodenya tidak dengan jalan penyatuan dengan Tuhan, melainkan dengan peneladanan pada Nabi dengan tetap ber-murâqabah pada ruhnya guna mencapai kesucian jiwa. ${ }^{49}$

Dalam usaha menarik pengikut, mereka menggunakan bentuk-bentuk organisasi sosial baru, yang terpusat dan tidak mudah pecah, jika dibandingkan dengan tarekat-tarekat Klasik, dan tidak jarang melibatkan diri secara aktif dalam urusan-urusan politis. ${ }^{50}$ Mereka tidak saja menyediakan pelayanan spiritual kepada para pengikutnya dalammencapai kesempurnaan jiwa, tetapi juga aktif melibatkan para pengikutnya dalam pemenuhan kewajiban-kebutuhan hidup, seperti berdagang dan mendirikan koperasi kerajian. ${ }^{51}$ Sanûsîyah dan Tijânîyah, hingga cabang-cabangnya di Sinegal, diketahui aktif melibatkan para pengikutnya (ikhwân) dalam pembuatan jalan raya, pembentukan koperasi dagang, pelaksanaan proyek-proyek irigasi, dan pengembangan komunitas pertanian. ${ }^{52}$

Tarekat-tarekat abad ke-19, bahkan, melangkah lebih jauh lagi, dengan melibatkan diri dalam kegiatan politik. Mewakili jaringan internasional bawah tanah, mereka berusaha melindungi identitas religio-kultural kaum Muslim dalam menghadapi penguasa-penguasa kolonial yang dianggap kafir. Untuk kepentingan ini, aktifisme tarekat mudah sekali berubah menjadi gerakan jihad guna melawan kekuatan-kekuatan yang dianggap musuh Islam. Tarekat Sanûsîyah di bawah Sayyîd al-Mahdî dan keturunannya harus mengangkat senjata melawan serbuan Italia. ${ }^{53}$ Syaikh-syaikh Naqsyabandiyah-Khalîdîyah memelopori gerakan perlawanan di beberapa wilayah barat terhadap agresi Kolonialis Eropa ${ }^{54}$ dan kawasan

${ }^{48}$ R.J.I. Ter Laan, "Sanusi Revivalism as Part of the Fundamentalist Tradition in Islam," dalam Nicola A. Ziadeh, Sanusiyah: A Study of a Revivalist Movement in Islam (Leiden: E.J. Brill, 1983), h. 140.

${ }^{49}$ Ibid., h.140.

${ }^{50}$ R.S. O'Fahey, Enigmatic Saint: Ahmad Ibn Idrisi and the Idrisi Tradistion (London: Hurst and Company, 1990) h. 4.

${ }^{51}$ Johns, "The Tariqah," h. 350.

${ }^{52}$ Ibid.

${ }^{53}$ Derek Hoopwood, "A Pattern of Revival Movements in Islam?," dalam Islamic Quarterly, Vol. 15-4, (1974) h. 157.

${ }^{54} \mathrm{Hamid}$ Algar, "The Naqsyabandi Order: A Preliminary Survey of its History and Significance," dalam Studia Islamica, XLIV, 1976, h. 151-152. 
Asia Tengah dari pendudukan Rusia. ${ }^{55}$ Qâdirîyah-Naqsyabandiyah Indonesia melawan kesewenangwenangan pemerintah kolonial Belanda. ${ }^{56} \mathrm{Jika}$ dikehendaki, keterlibatan tarekat dalam peperangan fisik melawan agresi penjajah dapat lebih diperpanjang daftarnya. Pertanyaannya, apakah sikap militansi menjadi ciri utama dari tarekat-tarekat baru, atau hanya kebetulan sifatnya? Atau contoh-contoh itu hanya pengecualian disebabkan situasi luar biasa, sedangkan kalangan tarekat, terutama masa-masa belakangan, biasanya cenderung apolitik?

Menurut Bruinessen, terdapat dua pandangan yang bertolak belakang terkait dengan tasawuf dan tarekat. Di mata para pejabat kolonial, tarekat dianggap sebagai sumber kecurigaan karena adanya fanatisme pada guru yang dengan mudah berubah menjadi fanatisme politik. Karena itu, bukan suatu kebetulan jika kajian-kajian Barat pertama mengenai tarekat lebih mirip laporan penyelidikan intel daripada penelitian ilmiah. Karena bahaya politik yang mereka cerna, banyak pejabat kolonial menganjurkan larangan atau pembatasan terhadap tarekat. Namun, kecurigaan terhadap tarekat sebenarnya bukan monopoli pejabat kolonial. Pemerintah Turki, sejak 1925 melarang semua tarekat, dan itu berlaku bahkan hingga sekarang, setelah terjadi pemberontakan nasional Kurdi di bawah pimpinan syaikh-syaikh Naqsyabandiyah. Larangan lebih ketat lagi berlaku di (bekas) Uni Soviet, karena jaringan tarekat merupakan oposisi bawah tanah yang paling penting di republik-republik bagian Uni Soviet tersebut. ${ }^{57}$

Pandangan kedua, sebaliknya, bahwa perkembangan tarekat merupakan gejala depolitisasi, sebagai bentuk pelarian dari tanggung jawab sosial-politik. Dalam konteks ini, kaum tarekat dianggap lebih berorientasi pada urusan ukhrawi daripada urusan duniawi dan mereka dikritik karena lebih menekankan aspek asketik (zuhd); dalam mendekatkan diri kepada Tuhan, mereka biasa menjauhkan diri dari masyarakat ('uzlah dan khalwat). Bila kalangan Islam tradisional dianggap lebih kolot dan akomodatif serta apolitik dibandingkan kalangan modernis, justru kaum tarekat dianggap paling kolot di antara yang kolot dan paling menghindar dari sikap politik. Pandangan seperti ini terkesan agak menyederhanakan, tetapi tidak dapat dimungkiri bahwa ada kaitan erat antara proses depolitisasi seperti kasus Indonesia dalam tiga dasawarsa belakangan, dan suburnya perkembangan tarekat. Namun jelas bahwa kedua pandangan tentang tarekat tersebut terkait dengan situasi-situasi yang berbeda. ${ }^{58}$

Dalam pengamatan Bruinessen, hampir semua kasus perlawanan fisik oleh kaum tarekat ditujukan kepada penguasa-penguasa non-Muslim atau sekuler (Turki). Di negaranegara Muslim, jarang sekali terjadi pemberontakan atau sikap oposisi radikal dari kaum tarekat. Di sini, sikap kaum tarekat tidak berbeda dengan kalangan Muslim tradisional umumnya. Bahkan, mereka sangat dekat dengan penguasa. Di negeri-negeri Muslim, termasuk Indonesia, syaikh-syaikh Naqsyabandiyah cenderung mendekati penguasa dan mencari pengikut

${ }^{55}$ Martin van Bruinessen, Tarekat Naqsyabandiyah di Indonesia (Bandung: Mizan, 1998) h.67.

${ }^{56}$ Johns, "Tariqah," h. 350.

${ }^{57}$ Martin van Bruinessen, Kitab Kuning Pesantren dan Tarekat: Tradisi-tradisi Islam di Indonesia (Bandung: Mizan, 1999) h. 333.

${ }^{58}$ Ibid., h. 335. 
di kalangan elit. Pihak yang disebut terakhir ini biasanya sangat "welcome," dan tampaknya ada semacam simbiosis mutualisme antara kedua belah pihak. Kedekatan para syaikh dengan penguasa setempat, selain membawa manfaat pribadi, dengan sendirinya-dan ini terbuktijuga dapat membantu mudahnya proses islamisasi lanjutan, khususnya di kalangan istana. Sedangkan bagi penguasa, karâmah dan kekuatan spiritual para syaikh diyakini bisa mendatangkan berkah bagi perlindungan dan pelestarian kerajaan dan kepentingan mereka. Tidak kalah penting, kedekatan penguasa dengan para syaikh, tentu saja dapat memperkokoh legitimasi mereka di mata rakyat.

Tarekat terbukti telah memainkan peranan penting dalam memperkuat persatuan dan jaringan sosial. Di kawasan Afrika, tempat banyak terdapat suku yang berbeda-beda dan saling bersaing serta terlibat peperangan, tarekat merekrut banyak pengikut dari mereka dan berhasil mendamaikan serta mempersatukan para pengikut tersebut, bahkan mengkoordinir mereka untuk kepentingan perjuangan. Negara Libya modern, misalnya, adalah hasil nyata dari perjuangan tarekat Sanûsîyah, dan syaikhnya yang keempat yaitu Sayyîd Muhammad Idrîs, menjadi raja pertama negara tersebut. ${ }^{59} \mathrm{Di}$ Kurdistan, peranan pemersatu bagi masyarakat Kurdi yang bersuku-suku dimainkan oleh tarekat Naqsyabandiyah di akhir abad ke-19. ${ }^{60}$ Di Indonesia, tarekat Qâdirîyah-Naqsyabandiyah memainkan peranan penting sebagai jaringan komunikasi dan koordinasi bagi para pengikutnya dalam perjuangan melawan Belanda. ${ }^{61}$ Di abad ke-20, peran sosial-politik tarekat tetap tidak bisa diabaikan, meski tujuannya bisa jadi berubah. Di Turki, meskipun masih dilarang, tarekat menjadi lumbung suara yang penting, dan para syaikh memainkan peranan politik yang menonjol, sebagai anggota parlemen sekaligus bisa menempatkan orang-orang kepercayaan mereka di jajaran birokrasi. Di Indonesia, kebijakan depolitisasi Islam yang diterapkan pemerintah Orde Baru juga telah menempatkan tarekat sebagai lumbung suara yang diperebutkan partai penguasa dan para pesaingnya. Kehadiran tarekat-tarekat baru di berbagai wilayah dunia Islam terbukti telah memainkan peran yang menentukan pada masa-masa genting maupun pada masa normal.

Demikianlah, corak tasawuf dan tarekat-tarekat baru yang muncul setelah terjadinya rekonsiliasi antara tasawuf dan syariat di abad ke-14, menunjukkan semakin kuatnya doktrin neosufisme memasuki lapangan tasawuf dan tarekat abad-abad sesudahnya, bahkan hingga masa modern. Pada dasarnya, neosufisme merupakan penghayatan batini (esoterisme) yang menghendaki hidup aktif dalam masalah-masalah kemasyarakatan, termasuk politik. Neosufisme muncul sebagai upaya menghidupkan kembali aktifisme salafi dalam hidup keberagamaan kaum Muslim dan menanamkan sikap positif pada dunia, yang sebelumnya tenggelam dalam pengaruh paham zuhud dalam tasawuf atau tarekat lama (klasik). Mendapat pengaruh neosufisme, tasawuf atau tarekat baru coraknya jauh lebih "revolusioner," baik dalam segi

${ }^{59}$ E.E. Evans Pritchard, The Sanusi of Cyrenaica (Oxford: Oxford University Press, 1949).

${ }^{60}$ Bruinessen, Kitab Kuning, h. 341.

${ }^{61}$ Sartono Kartodirjo, Pemberontakan Petani Banten 1888 (Jakarta: Pustaka Jaya, 1984) h. 225-231. 
kandungan doktrin maupun kelembagaannya. Dari segi doktrin, tasawuf atau tarekat baru dicirikan, antara lain, menolak penghormatan wali secara berlebihan, tidak mengenal ketatnya otoritas silsilah, bahkan ada yang menolak sama sekali, dan menjauhkan tasawuf dari asketisme, dengan titik berat pada aktifime-praktis. Selain itu, tujuan dzikir-nya mengarah pada penyatuan dengan ruh Nabi, bukan dengan Tuhan, sehingga mereka sering disebut dengan tasawuf atau tarekat Muhammadiyah, sebagai peneguhan bahwa tasawuf atau tarekat ini dimurnikan dengan bertitik tolak dari kehidupan moral-spiritual Nabi. ${ }^{62}$

Dari segi kelembagaan, tasawuf atau tarekat, baru sering dikatakan memiliki ciri khusus, dengan sistem organisasi yang agak terpusat dan tidak mudah pecah, jika dibandingkan dengan tasawuf atau tarekat-tarekat klasik. Dalam usaha menarik pengikut, mereka menggunakan bentuk-bentuk organisasi sosial baru, dan tidak jarang melibatkan diri secara aktif dalam urusan-urusan politis. ${ }^{63}$

Dengan karakteristik seperti itu, neosufisme dalam perkembangannya telah memberikan landasan yang kuat bagi munculnya banyak gerakan pemburuan, khususnya dalam tasawuf dan tarekat, baik bersifat damai maupun radikal, di berbagai penjuru dunia Muslim. Ketika penetrasi Barat dan kekuatan sekuler lainnya semakin dalam memasuki dunia Muslim, banyak tarekat atau tasawuf bernafaskan neosufisme menjadi kekuatan perlawanan kaum Muslim yang tangguh. Di masa-masa normal, tasawuf dan tarekat baru bisa menjadi patner yang setia dalam upaya mensukseskan program-program perbaikan kehidupan masyarakat, tanpa harus meninggalkan tugas utamanya untuk mendakwahkan kedamaian Islam kepada seluruh umat manusia.

Memperhatikan aktifivisme tasawuf dan tarekat baru sejak kemunculannya, kiranya tidak beralasan untuk terus mendiskreditkan keberadaannya dalam kehidupan kaum Muslim. Tasawuf dan tarekat yang dipegangi tokoh-tokoh sufi pemburu adalah tasawuf dan tarekat baru yang berbeda jauh dari gambaran yang selama ini dipegangi banyak orang bahwa tasawuf atau tarekat sering mengabaikan Islam (syariah), cenderung bersifat antinomian, eklektif dan eksesif. Keterlibatan guru-guru sufi atau syaikh-syaikh tarekat secara aktif dalam urusan duniawi, tanpa meninggalkan tanggung jawabnya dalam aspek esoterik-batiniah, sesungguhnya membuktikan bahwa tasawuf dan tarekat merupakan persambungan dari apa yang sering disebut dengan "neosufisme" telah memainkan peranan penting dalam membangkitkan optimisme baru dalam pembinaan kehidupan moral masyarakat secara konkrit.

\section{Penutup}

Kemunculan neosufisme abad ke-7 H/14 M sangat besar pengaruhnya terhadap perkembangan corak tasawuf dan tarekat-tarekat baru di dunia Islam pada abad-abad sesudahnya.

${ }^{62}$ Triminham, The Sufi Order, h. 106.

${ }^{63}$ O'Fahey, Enigmatic Saint, h. 4. 
Di lapangan tasawuf, neosufisme telah mendorongnya agar melakukan semacam "purifikasi" doktrin agar tidak terkontaminasi dengan unsur-unsur non Islam, serta tetap bertahan di jalur syariat. Neosufisme memberikan arah yang tidak putus-putusnya agar tasawuf senantiasa tetap berada dalam bimbingan syariat, dan syariat harus tetap menjadi bagian tidak terpisahkan dari doktrin tasawuf. Dorongan ini secara perlahan menjadikan tasawuf semakin memperlemah dukungannya untuk mempertahankan doktrin emanasi Tuhan atas makhluknya, digantikan dengan doktrin transendensi. Walau kecenderungannya terhadap doktrin Ibn 'Arabî tidak goyah, tasawuf senantiasa menempatkan doktrinnya dalam kerangka ortodoks, karena kesetiaannya pada syariat. Di lapangan tarekat, pengaruh neosufisme lebih hebat lagi. Pengembalian tarekat kepada ajaran sumber asli al-Qur'an dan Sunnah menjadikannya terbebaskan dari sifat-sifatnya yang tidak islami. Seperti halnya tasawuf, tarekat-tarekat baru juga memandang dunia lebih positif, bahkan cenderung bercorak aktivisme radikal bila kepentingan spiritualitas khususnya dan misi dakwah Islamiyah umumnya terganggu. Tidak bisa dimungkiri, kemunculan tasawuf dan tarekat-tarekat baru, dengan bentuk organisasinya yang trans-nasional, besar jasanya dalam turut menentukan corak puritanisme keberagamaan kaum Muslim pada umumnya serta sikap optimisme mereka dalam memandang dunia. Pembaruan doktrin dan watak yang dibawa gerakan neosufisme telah membawa tasawuf dan tarekat baru, tidak seperti yang citrakan banyak orang selama ini, mampu memainkan banyak peran duniawi, namun fungsi dan kehadiran utama mereka tetap sebagai kendaraan pendekatan diri dengan Tuhan dan menjalankan misi dakwah Islam.

\section{Pustaka Acuan}

Algar, Hamid. "The Naqsyabandi Order: a Preliminary Survey of its History and Significance," dalam Studia Islamica, XLIV, 1976.

Ansari, Abdul Haq. "Syah Wali Allah Attempts to Revise Wahdat al-Wujud," Arabica. Leiden: E.J. Brill, 1988.

Arberry, A.J. Sufism an Account of the Mystics of Islam. London: Mandala Books, 1979.

Al-Attas, Syed Muhammad Naquib. Some Aspects of Sufism as Understood and Practiced among the Malays. Singapore: Malayan Sociological Research Institute Ltd., 1983.

Azra, Azyumardi. Esei-esai Intelektual Muslim dan Pendidikan Islam. Ciputat: Logos Wacana Ilmu, 1999.

Azra, Azyumardi. Jaringan Ulama Timur Tengah dan Kepulauan Nusantara Abad XVII dan XVIII. Bandung: Mizan, 1994.

Bruinessen, Martin van. Kitab Kuning Pesantren dan Tarekat: Tradisi-tradisi Islam di Indonesia. Bandung: Mizan, 1999.

Bruinessen, Martin van. Tarekat Naqsyabandiyah di Indonesia. Bandung: Mizan, 1998.

Drewes, G.J.W. “Indonesia: Mistisisme dan Aktivisme," dalam Gustave E. von Grunebaum (ed). Islam Kesatuan dan Keragaman. Jakarta: Yayasan Perkhidmatan, 1975. 
Glasse, Cyril. The Consise Encyclopedia of Islam. London: Stancey International, 1989.

Hitti, Phillip K. History of the Arabs. London: Macmillan, 1973.

Hoopwood, Derek. "A Pattern of Revival Movements in Islam?," dalam Islamic Quartely, Vol. 15-4, 1974.

Husaini, S.A.Q. The Pantheistic Monism of Ibn Arabi. Lahore: S.H. Muhammad Ashraf, 1970.

Johns, A.H. "Tariqah," dalam Mircea Eliade (ed.), The Encyclopaedia of Religion. New York: Macmillan Publishing Company, 1987.

Kartodirjo, Sartono. Pemberontakan Petani banten 1888. Jakarta: Pustaka Jaya, 1984.

Laan, R.J.I. Ter. "Sanusi Revivalism as Part of the Fundamentalist Tradition in Islam," dalam Nicola A. Ziadeh. Sanusiyah a Study of a revivalist Movement in Islam. Leiden: E.J. Brill, 1983.

Lapidus, Ira M. History of Islamic Societies. Cambridge: Cambridge University Press, 1993.

Ma'luf, Abu Louis. Al-Munjid fĩ al-Lughah wa al-A'lam. Beirut: Dâr al-Masyriq, 1986.

MacDonald, D.B. "Sufism," dalam E.J. Brill's First Encyclopedia of Islam, Vol. III, Leiden: E.J.Brill, 1987.

Madjid, Nurcholish. Islam Agama Peradaban Membangun Makna dan Relevansi Doktrin Islam dalam Sejarah. Jakarta: Paramadina, 2000.

Massignon, Louis. "Tariqa," dalam E.J. Brill's First Encyclopaedia of Islam. Leiden: E.J. Brill, 1987.

Nicolson, Reynold A. "Sufism," dalam James Hastings. Encyclopaedia of Religion and Etics, Vol. XXII, Charles Scriber's, t.t.

O'Fahey, R.S. Enigmatic Saint: Ahmad Ibn Idrisi and the Idrisi Tradition. London: Hurst and Company, 1990.

Pritchard, E.E. Evans. The Sanusi of Cyrenaica. Oxford: Oxford University Press, 1949.

Rahman, Fazlur. Islam. Chicago: University of Chicago Press, 1979.

Rahman, Fazlur. "Islam: Challenges and Opportunities," dalam Alford T. Welch dan Pierre Cachia (ed.). Islam: Past Influence and Present Challenge. London: Edinburgh University Press, 1979.

Suriasumantri, Jujun S. "Penelitian Ilmiah, Kefilsafatan, dan Keagamaan: Mencari Paradigma Kebersamaan," dalam Mastuhu dan Deded Ridwan (ed.). Tradisi Baru Penelitian Agama Islam Tinjauan Antardisiplin Ilmu. Bandung: Nuansa, 1998.

Al-Taftazani, Abu al-Wafa' al-Ghanimi. Sufi dari Zaman ke Zaman, terj. Ahmad Rofi' Utsmani. Bandung: Pustaka, 1983.

Tibi, Bassam. Krisis Peradaban Islam Modern sebuah Kultur Praindustri dalam Era Ilmu Pengetahuan dan Teknologi, terj. Yudian W. Asmin, et al. Yogyakarta: Tiara Wacana, 1994.

Trimingham, J.S. The Sufi Orders in Islam. Oxford: Oxford University Press, 1979. 